\title{
Effect of dietary laminarin and fucoidan on selected microbiota, intestinal morphology and immune status of the newly weaned pig
}

\author{
A. M. Walsh ${ }^{1}$, T. Sweeney ${ }^{2}$, C. J. O'Shea ${ }^{1}$, D. N. Doyle ${ }^{1}$ and J. V. O'Doherty ${ }^{1 *}$ \\ ${ }^{1}$ School of Agriculture and Food Science, University College Dublin, Lyons Research Farm, Newcastle, County Dublin, \\ Republic of Ireland \\ ${ }^{2}$ School of Veterinary Medicine, University College Dublin, Belfield, Dublin 4, Republic of Ireland \\ (Submitted 12 September 2012 - Final revision received 12 February 2013 - Accepted 16 February 2013 - First published online 26 March 2013)
}

\section{Abstract}

A $2 \times 2$ factorial experiment was conducted to investigate the interactions between laminarin (LAM; 0 and 300 parts per million (ppm)) and fucoidan (FUC; 0 and $240 \mathrm{ppm}$ ) levels on intestinal morphology, selected microbiota and inflammatory cytokine gene expression in the weaned pig. There was an interaction between LAM and FUC supplementation on the Enterobacteriaceae population $(P<0 \cdot 05)$ and the abundance of attaching and effacing Escherichia coli (AEEC) strains $(P<0 \cdot 05)$ in the colon. Pigs offered the FUC diet had a reduced Enterobacteriaceae population compared with pigs offered the basal diet. However, the effect of FUC on the Enterobacteriaceae population was not observed when combined with LAM. Pigs offered the LAM diet had reduced abundance of AEEC strains compared with pigs offered the basal diet. However, there was no effect of LAM on the abundance of AEEC strains when combined with FUC. There was an interaction between LAM and FUC supplementation on villous height $(P<0 \cdot 01)$ and the villous height:crypt depth ratio $(P<0 \cdot 01)$ in the duodenum. Pigs offered the LAM or FUC diet had an increased villous height and villous height:crypt depth ratio compared with pigs offered the basal diet. However, there was no effect of the LAM and FUC combination diet on intestinal morphology. Pigs offered the LAM-supplemented diets had a lower $I L-6(P<0 \cdot 05), I L-17 A(P<0 \cdot 01)$ and $I L-1 \beta(P<0 \cdot 01)$ mRNA expression in the colon compared with pigs offered the diets without LAM. In conclusion, supplementation with either LAM or FUC alone modified intestinal morphology and selected intestinal microbiota, but these effects were lost when offered in combination.

\section{Key words: Fucoidan: Gastrointestinal health: Laminarin: Weaned pigs}

Pigs are confronted with multiple stressors during the postweaning period such as a change in diet, separation from the sow and exposure to unfamiliar pigs ${ }^{(1)}$. This situation generally results in low voluntary feed intake and suboptimal growth rate, both of which are associated with the effects on intestinal mucosal integrity and with the occurrence of pathological disorders ${ }^{(2)}$. Supplementation with in-feed antibiotics has been widely used to reduce pathogen infection in swine; however, the European Union ban of these in-feed antibiotics has prompted the search for alternatives.

Recently, seaweed extracts containing both laminarin (LAM) and fucoidan (FUC) have been explored as a novel source of bioactive compounds containing immunomodulatory and antimicrobial properties ${ }^{(3-5)}$. LAM and FUC are the main water-soluble polysaccharides of brown algae ${ }^{(6)}$. LAM represents a group of low-molecular-weight polysaccharides composed of $\beta$-(1 $\rightarrow 3)$-linked glucans with $\beta$ - $(1 \rightarrow 6)$-linked side chains of varying distribution and length ${ }^{(7,8)}$. LAM have shown promising antibacterial ${ }^{(9)}$ and immunomodulating activities $^{(10)}$. FUC is a sulphated polysaccharide, containing
L-fucose as one of the major monosaccharides ${ }^{(11)}$. Research has indicated that FUC may function as immunomodulatory ${ }^{(12)}$ and antibacterial agents ${ }^{(13)}$. Recently, O'Doherty et $a l^{(14)}$ found that the inclusion of a seaweed extract rich in both LAM and FUC increases the daily gain and the gain:feed ratio of pigs post-weaning mainly through improved nutrient digestibility and decreasing the faecal Escherichia coli population. However, the mode of action of the individual components of the seaweed extract is still unknown in the weaned pig's diet.

LAM and FUC may offer a dietary means to alter gut morphology and/or modulate immunity, thereby reducing the risk of diarrhoea and promoting growth performance in the absence of in-feed antibiotics. However, application of any alternative feed additive requires a detailed knowledge of the physiological effects. Therefore, the objective of the present experiment was to evaluate the effects of the dietary supplementation of LAM and FUC, independently or in combination, on gut morphology, selected intestinal microbiota populations, volatile fatty acid (VFA) concentrations

Abbreviations: AEEC, attaching and effacing Escherichia coli; FUC, fucoidan; LAM, laminarin; ppm, parts per million; VFA, volatile fatty acid. 
and inflammatory cytokine gene expression in the weaned pig. It is hypothesised that the inclusion of both LAM and FUC would improve the aspects of gastrointestinal health after weaning due to the biological properties of LAM and FUC, resulting in an altered microflora and immune response in the gastrointestinal tract of the weaned pig.

\section{Experimental methods}

All procedures described in the present experiment were conducted under experimental licence from the Irish Department of Health in accordance with the cruelty to Animals Act 1876 and the European Communities (Amendments of the Cruelty to Animals Act 1976) Regulations.

\section{Experimental diets}

The experiment was designed as a $2 \times 2$ factorial arrangement, comprising four dietary treatments. The dietary treatments were as follows: (1) basal diet; (2) basal diet +240 parts per million (ppm) FUC; (3) basal diet +300 ppm LAM; (4) basal diet $+300 \mathrm{ppm}$ LAM and $240 \mathrm{ppm}$ FUC. The concentrations of LAM and FUC used in the present study were based on previous work by Lynch et al. ${ }^{(9)}$ and McDonnell et al. ${ }^{(15)}$. LAM (990 g LAM/kg) and FUC (720 g FUC/kg, $180 \mathrm{~g} / \mathrm{kg}$ crude protein and $100 \mathrm{~g} / \mathrm{kg}$ ash) were derived from Laminaria spp. and sourced from BioAtlantis Limited (Kerry Technology Park). The diets were fed for $8 \mathrm{~d}$ ad libitum; after which time pigs were humanely killed. The diets were formulated to have similar digestible energy $(14.5 \mathrm{MJ} / \mathrm{kg})$ and standardised ileal digestible lysine $(12.5 \mathrm{~g} / \mathrm{kg})$ contents. All amino acid requirements were met relative to lysine ${ }^{(16)}$. The ingredient composition and chemical analysis of the dietary treatments are presented in Table 1.

\section{Animals and management}

A total of twenty-eight pigs (progeny of large white $\times$ (large white $\times$ landrace sows)) were selected from a commercial pig unit at $24 \mathrm{~d}$ of age. The pigs had a weaning weight of 6.9 (SD 0.50$) \mathrm{kg}$ and were blocked on the basis of litter of origin and body weight $(n 7)$. The pigs were individually housed in fully slated pens $(1.7 \mathrm{~m} \times 1.2 \mathrm{~m})$. They were individually fed and had ad libitum access to feed and water. The house temperature was thermostatically controlled at $30^{\circ} \mathrm{C}$ throughout the experiment. The pigs were weighed at the beginning of the experiment (day 0) and at the end of the experiment (day 8).

\section{Gut morphological analysis}

The pigs were humanely killed on day 8 by lethal injection with Euthatal (pentobarbitone sodium BP; Merial Animal Limited) at a rate of $1 \mathrm{ml} / 1.4 \mathrm{~kg}$ body weight. On removal of the digestive tract, sections of the duodenum $(10 \mathrm{~cm}$ from the stomach), the jejunum $(60 \mathrm{~cm}$ from the stomach) and the ileum $(15 \mathrm{~cm}$ from the caecum) were excised and fixed in $10 \%$ phosphate-buffered formalin. The preserved segments
Table 1. Composition and chemical analysis of the basal diet $(\mathrm{g} / \mathrm{kg}$, unless otherwise indicated)

\begin{tabular}{|c|c|}
\hline & Basal diet ${ }^{\star}$ \\
\hline \multicolumn{2}{|l|}{ Composition } \\
\hline Whey powder & $50 \cdot 0$ \\
\hline Wheat & $380 \cdot 0$ \\
\hline Barley & 233.5 \\
\hline Soyabean meal & $170 \cdot 0$ \\
\hline Full-fat soyabean & $120 \cdot 0$ \\
\hline Soya oil & $10 \cdot 0$ \\
\hline Vitamins and minerals $\dagger$ & $3 \cdot 0$ \\
\hline Salt & $3 \cdot 0$ \\
\hline Dicalcium phosphate & $12 \cdot 5$ \\
\hline Limestone & $11 \cdot 0$ \\
\hline Lys $\mathrm{HCl}$ & 4.0 \\
\hline DL-Met & 1.5 \\
\hline L-Thr & 1.5 \\
\hline \multicolumn{2}{|l|}{ Analysis composition } \\
\hline DM & $866 \cdot 1$ \\
\hline Crude protein $(\mathrm{N} \times 6.25)$ & $210 \cdot 6$ \\
\hline Neutral-detergent fibre & $115 \cdot 1$ \\
\hline Ash & 48.4 \\
\hline Gross energy $(\mathrm{MJ} / \mathrm{kg})$ & $16 \cdot 2$ \\
\hline Lys $\ddagger$ & 14.5 \\
\hline Met and Cysł & 8.4 \\
\hline Thr $\ddagger$ & $9 \cdot 1$ \\
\hline Trp $\ddagger$ & 2.5 \\
\hline Cał & 9.5 \\
\hline$P \ddagger$ & $6 \cdot 1$ \\
\hline \multicolumn{2}{|c|}{$\begin{array}{l}\text { *Treatments: (1) basal diet; (2) basal diet }+240 \text { parts per } \\
\text { million (ppm) fucoidan (FUC); (3) basal + } 300 \text { ppm laminarin } \\
\text { (LAM); (4) basal + } 300 \text { ppm LAM and } 240 \text { ppm FUC. } \\
\text { † Vitamin and mineral inclusion (per kg diet): Cu, } 25 ; \text { Zn, 100; } \\
\text { Se, 0.3; Mn, 25; I, 0.2; retinol, 0.3; cholecalciferol, 0.05; } \\
\alpha \text {-tocopherol, 40. } \\
\text { † Calculated for tabulated nutritional composition }{ }^{(51)} \text {. }\end{array}$} \\
\hline
\end{tabular}

were prepared using standard paraffin-embedding techniques. The samples were sectioned at a $5 \mu \mathrm{m}$ thickness and stained with haematoxylin and eosin ${ }^{(17)}$. Villous height and crypt depth were measured on the stained sections ( $4 \times$ objective) using a light microscope fitted with an image analyser (ImagePro Plus; Media Cybernetics). Measurements of fifteen welloriented and intact villi and crypts were taken for each segment. Villous height was measured from the crypt-villous junction to the tip. Crypt depth was measured from the crypt-villous junction to the base. Results are expressed as mean villous height or crypt depth in $\mu \mathrm{m}$.

\section{Extraction and enumeration of microbial DNA from the gastrointestinal tract digesta}

For microbial analysis, digesta samples (approximately 10 (SD 1) g) were aseptically recovered from the proximal colon of each pig immediately post-slaughter. The proximal colon is where we have previously observed much incidence of pathology and the region which has demonstrated the greatest response to dietary amendment with seaweed extracts. This reflects the dynamic microbial activity of the proximal colon before the recovery of moisture, as the digesta moves distally through the colon. Digesta samples were stored in sterile containers (Sarstedt), placed on ice and transported to the laboratory within $2 \mathrm{~h}$. The Lactobacillus population was enumerated as an example of changes in the population structure of 
Table 2. Oligonucleotide primers used for quantitative PCR to profile the selected bacteria in the colon

\begin{tabular}{|c|c|c|c|c|c|c|}
\hline Target bacteria & Forward primer $\left(5^{\prime} \rightarrow 3^{\prime}\right)$ & Reverse primer $\left(5^{\prime} \rightarrow 3^{\prime}\right)$ & $\begin{array}{l}\text { Amplicon } \\
\text { size (bp) }\end{array}$ & $T_{\mathrm{m}}\left({ }^{\circ} \mathrm{C}\right)$ & $\begin{array}{l}\text { Efficiency } \\
(\%)\end{array}$ & Reference \\
\hline Lactobacillus spp. & AGCAGTAGGGAATCTTCCA & CACCGCTACACATGGAG & 341 & 58 & 102.5 & Metzler-Zebeli et al. ${ }^{(52)}$ \\
\hline Enterobacteriaceae & $\begin{array}{l}\text { CATTGACGTTACCCGCAGAA } \\
\text { GAAGC }\end{array}$ & CTCTACGAGACTCAAGCTTGC & 190 & 58 & 98 & Metzler-Zebeli et al. ${ }^{(52)}$ \\
\hline AEEC strains & GGCGATTACGCGAAAGATAC & GATTAACCTCTGCCGTTCCA & 100 & 58 & 101 & Leverton \& Kaper ${ }^{(53)}$ \\
\hline
\end{tabular}

$T_{\mathrm{m}}$, annealing temperature; AEEC, attaching and effacing Escherichia coli.

potentially beneficial bacteria ${ }^{(18)}$, while the population of Enterobacteriaceae was enumerated as an example of potentially pathogenic bacteria ${ }^{(19)}$. The detection of the eae gene was taken as a marker for the presence of attaching and effacing E. coli (AEEC) strains that are characterised by their ability to cause lesions in the gut mucosa, leading to diarrhoeal disease as described previously by Krause et l $^{(20)}$ and Ochoa et al. ${ }^{(21)}$. Microbial genomic DNA was extracted from the digesta samples using a QIAamp DNA stool kit (Qiagen) in accordance with the manufacturer's instructions. The quantity and quality of DNA was assessed using a NanoDrop-ND1000 Spectrophotometer (Thermo Fisher Scientific, Inc.). Standard curves were prepared as described by O'Shea et al. ${ }^{(22)}$. Briefly, genomic DNA from all digesta samples was pooled and amplified through routine PCR using Lactobacillus, Enterobacteriaceae and eae-specific primers (Table 2). Serial dilutions of these amplicons served to generate standard curves using quantitative PCR (ABI 7500 Real-Time PCR System; Applied Biosystems Limited), permitting estimations of absolute quantification based on gene copies ${ }^{(23)}$. Quantitative PCR was performed in a final reaction volume of $20 \mu \mathrm{l}$ containing $1 \mu \mathrm{l}$ of template DNA, $1 \mu \mathrm{l}$ of forward and reverse primers (100 pM), $10 \mu \mathrm{l}$ of SYBR Green PCR Master Mix (Applied Biosystems Limited) and $8 \mu \mathrm{l}$ nuclease-free water. Thermal cycling conditions involved an initial denaturation step at $95^{\circ} \mathrm{C}$ for $10 \mathrm{~min}$ followed by forty cycles of denaturation at $95^{\circ} \mathrm{C}$ for $15 \mathrm{~s}$ and $65^{\circ} \mathrm{C}$ for 1 min. Dissociation analyses of the PCR product were performed to confirm the specificity of the resulting PCR products. Digesta samples were collected from the caecum and colon and were mixed with sodium benzoate and phenylmethylsulfonyl fluoride, in order to stop any bacterial activity and minimise the effects of post-thawing fermentation on resulting VFA concentrations. VFA analysis was performed using GLC according to the method described by Pierce et al. ${ }^{(17)}$.

\section{RNA extraction and complementary DNA synthesis}

Tissue samples were collected from the mesenteric side of the colon, rinsed with ice-cold sterile PBS (Oxoid) and stripped of overlying smooth muscle. The samples were then cut into small pieces using a sterile scalpel blade and stored in $15 \mathrm{ml}$ of RNAlater ${ }^{\mathrm{TM}}$ (Applied Biosystems) overnight followed by storage at $-20^{\circ} \mathrm{C}$ before RNA extraction. Total RNA was extracted from colonic tissue samples using a GenElute Mammalian Total RNA Miniprep Kit (Sigma-Aldrich Corporation) according to the manufacturer's instructions. To eliminate possible genomic DNA contamination, total RNA samples were subjected to DNase I (Sigma-Aldrich
Corporation) treatment according to the manufacturer's instructions. RNA was further purified using phenol-chloroform $^{(24)}$. Total RNA was quantified using a NanoDropND1000 Spectrophotometer (Thermo Fisher Scientific, Inc.) and purity was assessed by determining the ratio of absorbance at 260 and $280 \mathrm{~nm}$. All total RNA samples had $260: 280 \mathrm{~nm}$ ratios above $1 \cdot 8$. In addition, RNA integrity was verified by the visualisation of $18 \mathrm{~S}$ and $28 \mathrm{~S}$ ribosomal RNA bands following gel electrophoresis stained with ethidium bromide (Egel; Invitrogen, Inc.). Complementary DNA synthesis was performed using $1 \mu \mathrm{g}$ of total RNA and oligo $(\mathrm{dT})_{20}$ primers in a final reaction volume of $20 \mu \mathrm{l}$ using a Superscript $^{\mathrm{TM}}$ III First-Strand Synthesis Kit (Invitrogen Life Technologies) following the manufacturer's instructions.

\section{Quantitative PCR}

All primers for the selected cytokines, IL- $6, I L-8, T N F-\alpha$, $I L-17 A, I L-1 \beta$ and $I L-10$, are presented in Table 3 . The panels of pro- and anti-inflammatory cytokines chosen were selected based on previous work by Sweeney et al. ${ }^{(25)}$ and Leonard et al. ${ }^{(26)}$. Overall, eight previously validated reference genes $^{(27)}$ were evaluated for stability in a subset of samples using geNorm ${ }^{(28)}$, which included: $\beta$-actin $(A C T B) ; \beta 2$-microglobin $(B 2 M)$; glyceraldehyde-3-phosphate dehydrogenase $(G A P D H)$; peptidylprolyl isomerase A (PPIA); hypoxanthine ribose transferase cyclophilin (HPRT); tyrosine 3-monooxygenase/tryptophan 5-monooxygenase activation protein $\zeta$ polypeptide (YWHAZ); hydroxymethyl-bilane synthase (HMBS); $18 \mathrm{~S}$ ribosomal RNA (18S rRNA). HPRT and YWHAZ had the lowest stability $M$ value of all the reference genes tested and were therefore chosen for subsequent normalisation. The stability ' $M$ ' value generated by the geNorm application was less than 1.5 , which indicated their stability as endogenous controls (HPRT and YWHAZ) for these intestinal samples. Amplification was carried out in a reaction volume of $20 \mu \mathrm{l}$ containing $10 \mu \mathrm{l}$ of SYBR Green Fast PCR Master Mix (Applied Biosystems), forward and reverse primer mix $(1 \mu \mathrm{l}), 8 \mu \mathrm{l}$ of diethylpyrocarbonate-treated water and $1 \mu \mathrm{l}$ of template complementary DNA. Quantitative PCR was carried out using an ABI PRISM 7500 Fast Sequence Detection System for ninety-six well plates (Applied Biosystems). Thermal cycling conditions were as follows: an initial denaturation step at $95^{\circ} \mathrm{C}$ for $10 \mathrm{~min}$, forty cycles of denaturation at $95^{\circ} \mathrm{C}$ for $15 \mathrm{~s}$ followed by $60^{\circ} \mathrm{C}$ for $1 \mathrm{~min}$. Dissociation analysis of the PCR products was performed to confirm specificity. All samples were run in triplicate. Relative quantities for each target gene were generated by QBase software ${ }^{(29)}$ (Biogazelle). 
Table 3. Porcine oligonucleotide primers used for quantitative $\mathrm{PCR}^{*}$

\begin{tabular}{|c|c|c|c|c|c|}
\hline & Accession no. & Forward primer sequence $\left(5^{\prime} \rightarrow 3^{\prime}\right)$ & $T_{\mathrm{m}}\left({ }^{\circ} \mathrm{C}\right)$ & Reverse primer sequence $\left(5^{\prime} \rightarrow 3^{\prime}\right)$ & $T_{\mathrm{m}}\left({ }^{\circ} \mathrm{C}\right)$ \\
\hline \multicolumn{6}{|l|}{ Genes } \\
\hline IL-6 & NM-214399.1 & GACAAAGCCACCACCCCTAA & 59.8 & CTCGTTCTGTGACTGCAGCTTATC & $62 \cdot 7$ \\
\hline$I L-8$ & NM_213867.1 & CATGGACCAGAGCCAGAGAGAGA & $61 \cdot 8$ & GAAGGCAACAGCCAGTTGG & $59 \cdot 4$ \\
\hline$T N F-\alpha$ & NM_214022.1 & TGGCCCCTTGAGCATCA & $55 \cdot 2$ & CGGGCTTATCTGAGGTTTGAGA & $60 \cdot 3$ \\
\hline$I L-17 A$ & NM_001005729.1 & CCCTGTCACTGCTGCTTCTG & $61 \cdot 4$ & TCATGATTCCCGCCTTCAC & $56 \cdot 7$ \\
\hline$I L-1 \beta$ & NM_001005149.1 & TTGAATTCGAGTCTGCCCTGT & 59.4 & CCCAGGAAGACGGGCTTT & $57 \cdot 3$ \\
\hline$I L-10$ & NM_214041.1 & GCCTTCGGCCCAGTGAA & $57 \cdot 6$ & AGAGACCCGGTCAGCAACAA & 59.4 \\
\hline \multicolumn{6}{|c|}{ Reference genes } \\
\hline HPRT & NM_001032376.2 & TTGCTCGAGATGTGATGAAAGAG & 58.0 & TCCAGCAGGTCAGCAAAGAA & 58.0 \\
\hline YWHAZ & XM_001927228.1 & GGACATCGGATACCCAAGGA & $58 \cdot 0$ & AAGTTGGAAGGCCGGTTAATTT & 59.0 \\
\hline
\end{tabular}

$T_{\mathrm{m}}$, melting temperature; HPRT, hypoxanthine ribose transferase cyclophilin; YWHAZ, tyrosine 3-monooxygenase/tryptophan 5-monooxygenase activation protein $\zeta$ polypeptide.

${ }^{*}$ Primers were designed using Primer Express ${ }^{\mathrm{TM}}$ software and were synthesised by MWG Biotech.

\section{Laboratory analysis}

The total LAM content in the diets was determined using a commercial assay kit (K-YBGL; Megazyme International Ireland Limited). The FUC level in the diets was determined according to the method described by Usov et al. ${ }^{(30)}$. The feed samples were milled through a $1 \mathrm{~mm}$ screen (Christy and Norris Hammer Mill). The DM of the feed was determined after drying overnight at $103^{\circ} \mathrm{C}$. Ash was determined after ignition of a known weight of concentrate in a muffle furnace (Nabertherm) at $500^{\circ} \mathrm{C}$. The $\mathrm{N}$ content of the feed was determined using the LECO FP 528 instrument (Leco Instruments, UK Limited). The neutral-detergent fibre content was determined by the method of Van Soest et al. ${ }^{(31)}$ using the Ankom 220 Fibre Analyzer (Ankom ${ }^{\mathrm{TM}}$ Technology). The gross energy of the feed was determined using a Parr 1201 oxygen bomb calorimeter (Parr).

\section{Statistical analysis}

Experimental data were analysed as a $2 \times 2$ factorial, randomised complete block design using the general linear model procedure of $\mathrm{SAS}^{(32)}$. The statistical model used included the main effects of block, LAM and FUC supplemen- tation, and the associated interaction between LAM and FUC. The individual pig served as the experimental unit. Food intake was included as a covariate in the model for villous height, crypt depth and the villous height:crypt depth ratio in the digestive tract, but was not significant for any of the variables. Gene copy estimates of selected bacteria were log-transformed before statistical analysis. Data were checked for normality using the Proc Univariate function of SAS. Means were separated using the Tukey-Kramer test. Probability values of less than 0.05 were used as the criterion for statistical significance. All results are presented as least-square means with their standard errors.

\section{Results}

\section{Gut morphology}

The effects of purified LAM and/or FUC on villous height, crypt depth and the villous height:crypt depth ratio in the gastrointestinal tract are shown in Table 4. No effect was observed in either the jejunum or the ileum $(P>0.05)$. However, a significant interaction between LAM and FUC supplementation on villous height $(P<0 \cdot 01)$ and the villous height:crypt depth ratio $(P<0 \cdot 01)$ was observed in the

Table 4. Effect of purified laminarin (LAM) and/or fucoidan (FUC) on villous height, crypt depth and the villous height:crypt depth ratio in the gastrointestinal tract of the weaned pig

(Least-square mean values with their standard errors, $n 7$ pigs per treatment)

\begin{tabular}{|c|c|c|c|c|c|c|c|c|}
\hline \multirow[b]{2}{*}{ FUC $(p p m) \ldots$} & \multicolumn{4}{|c|}{ Treatment } & \multirow[b]{2}{*}{ SEM } & \multicolumn{3}{|c|}{ Significance } \\
\hline & 0 & 240 & 0 & 240 & & LAM & FUC & $\mathrm{LAM} \times \mathrm{FUC}$ \\
\hline LAM (ppm)... & 0 & 0 & 300 & 300 & & & & \\
\hline \multicolumn{9}{|c|}{ Villous height $(\mu \mathrm{m})$} \\
\hline Duodenum & $319^{a}$ & $377^{\mathrm{b}}$ & $381^{\mathrm{b}, \mathrm{c}}$ & $331^{a}$ & $16 \cdot 3$ & NS & NS & 0.003 \\
\hline Jejunum & 332 & 305 & 353 & 325 & $17 \cdot 3$ & NS & NS & NS \\
\hline Ileum & 277 & 246 & 263 & 278 & $15 \cdot 4$ & NS & NS & NS \\
\hline \multicolumn{9}{|c|}{ Crypt depth $(\mu \mathrm{m})$} \\
\hline Duodenum & 306 & 314 & 284 & 294 & $14 \cdot 6$ & NS & NS & NS \\
\hline Jejunum & 300 & 288 & 276 & 291 & $13 \cdot 2$ & NS & NS & NS \\
\hline Ileum & 269 & 253 & 259 & 289 & $15 \cdot 8$ & NS & NS & NS \\
\hline \multicolumn{9}{|c|}{ Villous height:crypt depth ratio } \\
\hline Duodenum & $1.07^{a}$ & $1 \cdot 27^{\mathrm{b}, \mathrm{c}}$ & $1.37^{\mathrm{C}}$ & $1 \cdot 15^{a, b}$ & 0.07 & NS & NS & 0.008 \\
\hline Jejunum & $1 \cdot 16$ & 1.12 & $1 \cdot 30$ & $1 \cdot 14$ & 0.07 & NS & NS & NS \\
\hline Ileum & 1.09 & 1.00 & 1.05 & 0.99 & 0.08 & NS & NS & NS \\
\hline
\end{tabular}

ppm, Parts per million.

a,b,c Mean values with unlike superscript letters were significantly different $(P<0.05)$. 
duodenum. Pigs offered the LAM or FUC diet alone had an increased villous height and villous height:crypt depth ratio in the duodenum compared with pigs offered the basal diet. However, there was no effect of LAM in the diet on gut morphology when included with FUC.

\section{Microbiology}

The effects of purified LAM and/or FUC on faecal scoring and selected microbial populations in the proximal colon of the pig are shown in Table 5. There was a significant interaction between LAM and FUC supplementation on the faecal score $(P<0 \cdot 01)$. Pigs offered the LAM or FUC diet alone had a decreased faecal score compared with pigs offered the basal diet. However, there was no effect of the LAM and FUC combination diet on the faecal score. There was no effect of the dietary treatment on the Lactobacillus population $(P>0.05)$ in the colon. There was a significant interaction between LAM and FUC supplementation on the Enterobacteriaceae population $(P<0.05)$ in the colon. Pigs offered the FUC diet alone had a reduced Enterobacteriaceae population compared with pigs offered the basal diet. However, there was no effect of FUC when combined with LAM on the Enterobacteriaceae population. There was a significant interaction between LAM and FUC supplementation on the abundance of AEEC strains in the colon $(P<0.05)$. Pigs offered the LAM diet alone had reduced abundance of AEEC strains compared with pigs offered the basal diet. However, there was no effect of LAM when combined with FUC on the abundance of AEEC strains.

\section{Cytokine gene expression analysis}

The effects of purified LAM and/or FUC on cytokine gene expression in colonic tissues of the pig are shown in Table 6. There was no interaction $(P>0.05)$ between LAM and FUC supplementation on $I L-1 \beta, I L-6$ or $I L-17 A$ mRNA expression $(P<0.05)$ in the colon. Pigs offered the LAMsupplemented diets had a significantly lower $I L-1 \beta, I L-\sigma$ and $I L-17 A$ mRNA expression in the colon compared with pigs offered the diets without LAM supplementation. There was a significant interaction between LAM and FUC supplementation on $I L-10$ mRNA expression $(P<0.05)$ in the colon. Pigs offered the LAM diet alone had a reduced $I L-10$ mRNA expression compared with pigs offered the basal diet. However there was no effect of LAM when in combination with FUC on $I L-10$ mRNA expression. There was no effect of FUC alone on the expression of inflammatory cytokines (IL- $6, I L-8, T N F-\alpha$, $I L-17 A, I L-1 \beta$ and $I L-1 O)$ in the colon $(P>0.05)$.

\section{Volatile fatty acids}

The effects of purified LAM and/or FUC on the total VFA concentrations are shown in Table 7 . There was no interaction $(P>0.001)$ between LAM and FUC supplementation on total VFA and acetic acid concentrations in the caecum. Pigs offered the LAM-supplemented diets had increased concentrations of total VFA and acetic acid in the caecum compared with pigs offered the diets without LAM supplementation. There was an interaction between LAM and FUC supplementation on the concentrations of isobutyric acid $(P<0 \cdot 01)$, isovaleric acid $(P<0.05)$, valeric acid $(P<0.05)$ and branched-chain fatty acids $(P<0.05)$ in the caecum. Pigs offered the FUC diet alone had decreased concentrations of isovaleric acid, valeric acid and branched-chain fatty acids compared with pigs offered the basal diet. However, there was no difference in the concentrations of these VFA when these pigs were offered the diets containing a combination of LAM and FUC compared with pigs offered the diets containing LAM alone. Pigs offered the FUC diet alone had increased concentrations of isobutyric acid compared with pigs offered the basal diet. However, pigs offered the diets containing a combination of LAM and FUC had similar concentrations of isobutyric acid compared with pigs offered the diets containing LAM alone.

There was a significant interaction between LAM and FUC supplementation on the concentrations of valeric acid and branched-chain fatty acids $(P<0 \cdot 05)$ in the colon. Pigs offered the FUC diet alone had decreased concentrations of branchedchain fatty acids compared with pigs offered the basal diet. However, there was no difference in the concentration of branched-chain fatty acids when these pigs were offered the diets containing a combination of LAM and FUC compared with pigs offered the diets containing LAM alone. Pigs offered the LAM diet alone had a decreased concentration of valeric acid compared with pigs offered the basal diet. However,

Table 5. Effect of purified laminarin (LAM) and/or fucoidan (FUC) on faecal scoring and selected microbial populations in the proximal colon of the weaned pig

(Least-square mean values with their standard errors, $n 7$ pigs per treatment)

\begin{tabular}{|c|c|c|c|c|c|c|c|c|}
\hline \multirow[b]{2}{*}{ FUC (ppm)... } & \multicolumn{4}{|c|}{ Treatment } & \multirow[b]{2}{*}{ SEM } & \multicolumn{3}{|c|}{ Significance } \\
\hline & 0 & 240 & 0 & 240 & & LAM & FUC & LAM $\times$ FUC \\
\hline LAM (ppm)... & 0 & 0 & 300 & 300 & & & & \\
\hline \multicolumn{9}{|l|}{ Faeces scoring } \\
\hline Days 0-8 & $4 \cdot 01^{\mathrm{b}}$ & $3.45^{\mathrm{a}}$ & $3.39^{a}$ & $3 \cdot 77^{a, b}$ & 0.15 & NS & NS & 0.005 \\
\hline \multicolumn{9}{|c|}{ Proximal colonic bacterial population (log gene copy number/g digesta) } \\
\hline Lactobacillus & $10 \cdot 3$ & $10 \cdot 2$ & $10 \cdot 4$ & 9.59 & 0.28 & NS & NS & NS \\
\hline Enterobacteriaceae & $7.94^{\mathrm{b}}$ & $6 \cdot 72^{\mathrm{a}}$ & $7 \cdot 76^{\mathrm{b}}$ & $8 \cdot 44^{b}$ & 0.35 & 0.043 & NS & 0.015 \\
\hline AEEC strains & $5 \cdot 89^{b}$ & $5 \cdot 21^{a, b}$ & $4.99^{a}$ & $5 \cdot 76^{a, b}$ & 0.33 & NS & NS & 0.036 \\
\hline
\end{tabular}

AEEC, attaching and effacing Escherichia coli.

${ }^{a, b}$ Mean values with unlike superscript letters were significantly different $(P<0.05)$. 
Table 6. Effect of purified laminarin (LAM) and/or fucoidan (FUC) on the immune response in proximal colonic tissues

(Least-square means of the relative abundance of each gene of interest with their standard errors, $n 7$ pigs per treatment)

\begin{tabular}{|c|c|c|c|c|c|c|c|c|}
\hline \multirow[b]{2}{*}{ FUC (ppm)... } & \multicolumn{4}{|c|}{ Treatment } & \multirow[b]{2}{*}{ SEM } & \multicolumn{3}{|c|}{ Significance } \\
\hline & 0 & 240 & 0 & 240 & & LAM & FUC & $\mathrm{LAM} \times \mathrm{FUC}$ \\
\hline $\begin{array}{l}\text { LAM }(p p m) \ldots \\
\text { Genes }\end{array}$ & 0 & 0 & 300 & 300 & & & & \\
\hline IL-6 & 1.45 & 1.06 & 0.44 & 0.81 & 0.26 & 0.024 & NS & NS \\
\hline IL-8 & 1.20 & 1.23 & 0.90 & 0.95 & 0.24 & NS & NS & NS \\
\hline$I L-10$ & $1.43^{\mathrm{b}}$ & $1.06^{a, b}$ & $0.62^{\mathrm{a}}$ & $0.99^{a, b}$ & 0.18 & 0.022 & NS & 0.049 \\
\hline$T N F-\alpha$ & 1.20 & 0.99 & 0.89 & 0.86 & 0.21 & NS & NS & NS \\
\hline$I L-17 A$ & 1.44 & 1.08 & 0.81 & 0.80 & 0.16 & 0.008 & NS & NS \\
\hline$I L-1 \beta$ & 1.60 & 1.37 & 0.78 & 0.82 & 0.23 & 0.008 & NS & NS \\
\hline
\end{tabular}

${ }^{\mathrm{a}, \mathrm{b}}$ Mean values with unlike superscript letters were significantly different $(P<0.05)$.

there was no difference in the concentration of valeric acid when these pigs were offered the diets containing a combination of LAM and FUC compared with pigs offered the diets containing FUC alone.

\section{Discussion}

Recently, O'Doherty et $a l^{(14)}$ have shown the benefits of using a diet supplemented with seaweed extract containing a combination of LAM and FUC on post-weaning growth performance. The present study was designed to examine the effects of including purified LAM or FUC independently in weaned pig diets in order to understand the possible mode of action of each bioactive compound and their potential as alternatives to in-feed antibiotics. The results of the present study show that either purified LAM or FUC alone modified intestinal morphology and selected intestinal microbiota; however, these effects were not detected when the purified extracts were offered in combination. Furthermore, LAM inclusion alone down-regulated the gene expression of a selected panel of inflammatory cytokines in the colon.

Supplementation of either purified LAM or FUC exerted a positive influence on intestinal morphology in pigs $8 \mathrm{~d}$ postweaning. This included an increase in villous height and the villous height:crypt depth ratio in the duodenum. This is an important observation as negative alterations normally occur in the intestinal morphology of pigs during the initial postweaning period including reduced villous height and, to a lesser extent, reduced crypt depth ${ }^{(33)}$. Variations in villous height and the villous height:crypt ratio are a good indicator of variations in nutrient digestion and the absorption capacity of the small intestine ${ }^{(33,34)}$.

In the present study, dietary consumption of FUC alone decreased the populations of Enterobacteriaceae in the

Table 7. Effect of purified laminarin (LAM) and/or fucoidan (FUC) on the total volatile fatty acid (VFA) concentrations in the caecum and colon of the weaned pig

(Least-square mean values with their standard errors, $n 7$ pigs per treatment)

\begin{tabular}{|c|c|c|c|c|c|c|c|c|}
\hline \multirow[b]{2}{*}{ FUC (ppm)... } & \multicolumn{4}{|c|}{ Treatment } & \multirow[b]{2}{*}{ SEM } & \multicolumn{3}{|c|}{ Significance } \\
\hline & 0 & 240 & 0 & 240 & & LAM & FUC & LAM $\times$ FUC \\
\hline LAM (ppm). & 0 & 0 & 300 & 300 & & & & \\
\hline \multicolumn{9}{|l|}{ Caecum } \\
\hline Total VFA (mmol/g digesta) & $92 \cdot 0$ & $99 \cdot 0$ & 106 & 112 & 0.80 & 0.001 & 0.001 & NS \\
\hline Acetic acid & $49 \cdot 6$ & $53 \cdot 7$ & $62 \cdot 4$ & $60 \cdot 8$ & 1.65 & 0.001 & NS & NS \\
\hline Propionic acid & $32 \cdot 1$ & 29.5 & $29 \cdot 6$ & 27.4 & 3.01 & NS & NS & NS \\
\hline Isobutyric acid & $0.90^{\mathrm{a}}$ & $1.45^{\mathrm{b}}$ & $1 \cdot 34^{\mathrm{a}, \mathrm{b}}$ & $0.97^{\mathrm{a}}$ & $0 \cdot 16$ & NS & NS & 0.009 \\
\hline Butryic acid & $12 \cdot 2$ & 9.65 & 11.4 & 14.0 & 2.50 & NS & NS & NS \\
\hline Isovaleric acid & $0.99^{c}$ & $0.22^{a}$ & $0.47^{a, b}$ & $0.65^{\mathrm{b}, \mathrm{c}}$ & 0.17 & NS & NS & 0.011 \\
\hline Valeric acid & $2 \cdot 67^{b}$ & $1 \cdot 14^{a}$ & $1.64^{a, b}$ & $3 \cdot 20^{\mathrm{b}}$ & 0.55 & NS & NS & 0.010 \\
\hline Branched-chained VFA & $4.57^{b}$ & $2 \cdot 88^{\mathrm{a}}$ & $3.45^{a, b}$ & $4 \cdot 82^{\mathrm{b}}$ & 0.64 & NS & NS & 0.025 \\
\hline \multicolumn{9}{|l|}{ Colon } \\
\hline Total VFA (mmol/g digesta) & 105 & 101 & 108 & 110 & $7 \cdot 31$ & NS & NS & NS \\
\hline Acetic acid & 57.9 & $52 \cdot 7$ & $61 \cdot 0$ & $59 \cdot 3$ & 3.79 & NS & NS & NS \\
\hline Propionic acid & 29.6 & $30 \cdot 7$ & $28 \cdot 1$ & $28 \cdot 8$ & 2.57 & NS & NS & NS \\
\hline Isobutyric acid & 1.43 & 1.22 & 1.31 & 1.51 & 0.13 & NS & NS & NS \\
\hline Butryic acid & 11.8 & $12 \cdot 3$ & $13 \cdot 2$ & 14.9 & $2 \cdot 22$ & NS & NS & NS \\
\hline Isovaleric acid & 3.05 & 2.43 & 2.29 & 3.90 & 0.36 & NS & NS & NS \\
\hline Valeric acid & $3.05^{\mathrm{a}}$ & $2 \cdot 43^{\mathrm{a}, \mathrm{b}}$ & $2 \cdot 29^{b}$ & $3 \cdot 90^{\mathrm{a}, \mathrm{b}}$ & 0.55 & NS & NS & 0.050 \\
\hline Branched-chain fatty acids & $5 \cdot 89^{b}$ & $4.53^{\mathrm{a}}$ & $5 \cdot 18^{a, b}$ & $7 \cdot 25^{\mathrm{c}}$ & 0.67 & NS & NS & 0.019 \\
\hline
\end{tabular}

${ }^{\mathrm{a}, \mathrm{b}, \mathrm{c}}$ Mean values with unlike superscript letters were significantly different $(P<0.05)$. 
colon. In agreement, Reilly et $a l{ }^{(3)}$ reported reductions in the Enterobacteriaceae population in the caecum and colon with the inclusion of seaweed extract containing a combination of LAM and FUC. FUC from different species of brown algae has been shown to inhibit the attachment of certain bacterial species in the porcine gastrointestinal tract as well as to prevent the binding of enterococci and streptococci species ${ }^{(13)}$ to the extracellular matrix proteins of animal cells. An inhibition of Enterobacteriaceae could prevent or decrease the severity of diarrhoea that appears after weaning ${ }^{(35)}$. This was reflected in the present study where pigs offered the FUC diet alone had a reduction in Enterobacteriaceae counts and displayed improved faecal consistency.

In the present study, the expression of a panel of pro- and anti-inflammatory cytokines ( $I L-6, I L-17 A, I L-1 \beta$ and $I L-10$ ) was down-regulated in the colon of pigs $8 \mathrm{~d}$ post-weaning following exposure to LAM. This is in agreement with a previous study in which the supplementation of $\beta$-glucans derived from Laminaria digitata, Laminaria byperborea and Saccharomyces cerevisiae reduced the expression of a number of pro-inflammatory cytokine genes in the colon ${ }^{(25)}$. Anti-inflammatory cytokines such as $I L-10$ play an important role in maintaining the balance between pro- and anti-inflammatory mediators $^{(36)}$. In the present study, the anti-inflammatory cytokine $I L-10$ was down-regulated, which may reflect the decrease in the pro-inflammatory cytokines observed, as a spike in pro-inflammation would probably increase antiinflammatory cytokines such as $I L-10$. Both in vitro and in vivo investigations have shown that overproduction of pro-inflammatory cytokines can reduce barrier integrity and alter epithelial permeability ${ }^{(37)}$. The anti-inflammatory effects of LAM may be attributed to a reduction of pathogen numbers, as was observed in the colon in the present study. The immunomodulatory effects of dietary LAM may be due to an indirect effect of LAM on the modulation of intestinal microbiota. If the supplementation of LAM suppresses the secretion of proinflammatory cytokines, then less activation of the immune system during the weaning period would be achieved, which could result in an improvement in growth performance $^{(38)}$. In a previous study, McDonnell et al. ${ }^{(15)}$ reported the enhanced growth performance of pigs post-weaning with the dietary inclusion of dietary LAM.

Attaching and AEEC can be divided into two main pathogroups that are enteropathogenic E. coli and enterohaemorrhagic E. coli ${ }^{(39)}$. Enteropathogenic E. coli and enterohaemorrhagic E. coli are implicated in post-weaning diarrhoea in pigs due to their ability to cause 'attaching and effacing' lesions ${ }^{(40-42)}$. This supports the observations in the present study, where LAM supplementation alone reduced the abundance of AEEC strains in the colon while also improving the faecal score of weaned pigs. The lower abundance of AEEC strains could be attributed to a number of reasons. First, the reduction in the abundance of AEEC strains may be attributed to the agglutination properties of LAM, which is a novel source of $\beta-(1 \rightarrow 3) /(1 \rightarrow 6)$ glucans. Yeast-derived $\beta$-glucans have the capacity to agglutinate certain bacterial species, thus inhibiting subsequent attachment and colonisation of epithelial mucosal surfaces ${ }^{(43)}$. Second, it could be due to a host immune response following the consumption of LAM. Innate immune signalling has recently been shown to alter the composition of the microbiota, which consequently influences the development of disease ${ }^{(44,45)}$. Recent studies have suggested that certain pathogens exploit this relationship, and as a mechanism of pathogenesis, these pathogens promote intestinal inflammation to create a more favourable environment for growth $^{(45)}$. In the present study, decreased inflammatory cytokine gene expression of the animals receiving the LAM diet alone may have promoted a more stable ecosystem that may have prevented the proliferation of some particular bacterial groups. Previous studies have suggested that inflammation induced in response to Salmonella enterica serovar Typhimurium alters luminal conditions and shifts growth competition in favour of the pathogen ${ }^{(46)}$. This may support the view that strains of $E$. coli have an advantage under conditions of inflammation, thus the inclusion of LAM alone decreasing the inflammatory response in the present study may partly account for the lower abundance of AEEC strains observed.

Previous research has focused on the dietary provision of seaweed extract containing both LAM and FUC, and found beneficial effects on post-weaning growth performance and selected faecal microbiota ${ }^{(4,14)}$. It was observed from the results of the present experiment that either LAM or FUC alone could modulate intestinal morphology and selected intestinal microbiota; however, these effects were absent when offered in combination. The difference observed between studies may be due to a number of reasons. First, the interaction between LAM and FUC on branched-chain fatty acids in the caecum and proximal colon may help explain the findings with the combination treatment in the present study. The increase in Enterobacteriaceae numbers and branched-chain fatty acids would indicate the promotion of protein fermentation when the two algal polysaccharides are offered in combination compared with the FUC diet alone. O'Shea et al. ${ }^{(47)}$ showed an association between an increase in Enterobacteriaceae numbers and protein fermentation in the distal gastrointestinal tract. Branched-chain fatty acids mainly originate from protein fermentation ${ }^{(48,49)}$. Such fermentation can lead to the formation of toxic metabolites such as $\mathrm{NH}_{3}$ and amines, which have been implicated in the clinical expression of diarrhoea ${ }^{(50)}$. Similar results have been reported previously where grower-finisher pigs offered a combination of LAM and FUC increased Enterobacterium spp. and protein fermentation in the colon compared with pigs offered FUC alone ${ }^{(9)}$. Other reasons for the differences in responses observed between studies may be due to the variation in the purity of LAM and FUC between studies. In the present study, LAM and FUC were prepared as individual purified bioactive compounds, where individual purified components were extracted from the cell wall. Previous studies have utilised a more crude single extract of seaweed, where intact combinations of LAM and FUC are still in an intact complex and are probably less available. Third, another possible reason for the inconsistent results observed between studies may be due to the variations in experimental design and diet composition. The experimental period in previous studies $^{(4,14)}$ using seaweed extracts was longer (21-28d) 
compared with the $8 \mathrm{~d}$ experimental period used in the present study. The interaction between LAM and FUC observed in the present study suggests distinct modes of action and the non-additive effects of these bioactive compounds.

The results of the present study show that supplementation with either purified LAM or FUC alone modified intestinal morphology and selected intestinal microbiota; however, these effects were not observed when offered in combination. Furthermore, the dietary inclusion of LAM alone had the added benefit of reducing inflammatory cytokine gene expression in the colon. The data suggest that LAM may have a different mode of action from FUC. Collectively, these results provide support that the inclusion of LAM alone was more beneficial than the FUC diet only or the combination treatment for weaned pigs. Future further studies will explore the effects of these bioactive compounds on growth performance and their potential to prevent the negative impact of a pathogen challenge.

\section{Acknowledgements}

Funding for the present study was provided by the Innovation Partnership Programme (Enterprise Ireland) and BioAtlantis Limited. A. M. W. wrote the manuscript, collected the samples and carried out the laboratory analysis. J. V. O'. D. designed the study, analysed the data and participated in the writing and correcting of the manuscript. T. S. designed the study and participated in the writing and correcting of the manuscript. C. J. O'. S. contributed towards the sample collection and laboratory analysis. D. N. D. contributed towards the sample collection. None of the authors had any conflict of interest.

\section{References}

1. Spreeuwenberg MAM, Verdonk JMAJ, Gaskins HR, et al. (2001) Small intestine epithelial barrier function is compromised in pigs with low feed intake at weaning. J Nutr $\mathbf{1 3 1}$, $1520-1527$.

2. Pluske JR, Hampson DJ \& Williams IH (1997) Factors influencing the structure and function of the small intestine in the weaned pig: a review. Livest Prod Sci 51, 215-236.

3. Reilly P, O'Doherty JV, Pierce KM, et al. (2008) The effects of seaweed extract inclusion on gut morphology, selected intestinal microbiota, nutrient digestibility, volatile fatty acid concentrations and the immune status of the weaned pig. Animal 2, 1465-1473.

4. Gahan DA, Lynch MB, Callan JJ, et al. (2009) Performance of weanling piglets offered low-, medium- or high-lactose diets supplemented with a seaweed extract from Laminaria spp. Animal 3, 24-31.

5. Leonard SG, Sweeney T, Bahar B, et al. (2011) Effect of dietary seaweed extracts and fish oil supplementation in sows on performance, intestinal microflora, intestinal morphology, volatile fatty acid concentrations and immune status of weaned pigs. Br J Nutr 105, 549-560.

6. Michell C, Lahaye M, Bonnet C, et al. (1996) In vitro fermentation by human faecal bacteria of total and purified dietary fibres from brown seaweeds. Br J Nutr 75, 263-280.
7. Read SM, Currie G \& Bacic A (1996) Analysis of the structural heterogeneity of laminarin by electrospray-ionisation-mass spectrometry. Carbohydr Res 281, 187-201.

8. Brown GD \& Gordon S (2005) Immune recognition of fungal $\beta$-glucans. Cell Microbiol 7, 471-479.

9. Lynch MB, Sweeney T, Callan JJ, et al. (2010) The effect of dietary Laminaria-derived laminarin and fucoidan on nutrient digestibility, nitrogen utilisation, intestinal microflora and volatile fatty acid concentration in pigs. J Sci Food Agric 90, 430-437.

10. Rice PJ, Adams EL, Ozment-Skelton T, et al. (2005) Oral delivery and gastrointestinal absorption of soluble glucans stimulate increased resistance to infectious challenge. J Pharmacol Exp Ther 314, 1079-1086.

11. Berteau O \& Mulloy B (2003) Sulfated fucans, fresh perspectives: structures, functions, and biological properties of sulfated fucans and an overview of enzymes active toward this class of polysaccharide. Glycobiology 13, 29R-40R.

12. Cumashi A, Ushakova NA, Preobrazhenskaya ME, et al. (2007) A comparative study of the anti-inflammatory, anticoagulant, antiangiogenic, and antiadhesive activities of nine different fucoidans from brown seaweeds. Glycobiology 17, 541-552.

13. Shibata H, Iimuro M, Uchiya $\mathrm{N}$, et al. (2003) Preventive effects of Cladosiphon fucoidan against Helicobacter pylori infection in Mongolian gerbils. Helicobacter 8, 59-65.

14. O'Doherty JV, Dillon S, Figat S, et al. (2010) The effects of lactose inclusion and seaweed extract derived from Laminaria spp. on performance, digestibility of diet components and microbial populations in newly weaned pigs. Anim Feed Sci Technol 157, 173-180.

15. McDonnell P, Figat S \& O' Doherty JV (2010) The effect of dietary laminarin and fucoidan in the diet of the weanling piglet on performance, selected faecal microbial populations and volatile fatty acid concentrations. Animal 4, 579-585.

16. NRC (1998) Nutrient Requirements of Swine, 10th ed. Washington, DC: National Academy Press.

17. Pierce KM, Sweeney T, Brophy PO, et al. (2006) The effect of lactose and inulin on intestinal morphology, selected microbial populations and volatile fatty acid concentrations in the gastro-intestinal tract of the weanling pig. Anim Sci 82, 311-318.

18. Leser TD, Amenuvor JZ, Jensen TK, et al. (2002) Culture-independent analysis of gut bacteria: the pig gastrointestinal tract microbiota revisited. Appl Environ Microbiol 68, 673-690.

19. Manzanilla EG, Perez JF, Martin M, et al. (2004) Effect of plant extracts and formic acid on the intestinal equilibrium of early-weaned pigs. J Anim Sci 82, 3210-3218.

20. Krause G, Zimmermann S \& Beutin L (2005) Investigation of domestic animals and pets as a reservoir for intimin- (eae) gene positive Escherichia coli types. Vet Microbiol 106, 87-95.

21. Ochoa TJ, Barletta F, Contreras C, et al. (2008) New insights into the epidemiology of enteropathogenic Escherichia coli infection. Trans R Soc Trop Med Hyg 102, 852-856.

22. O'Shea CJ, Sweeney T, Bahar B, et al. (2012) Indices of gastrointestinal fermentation and manure emissions of growingfinishing pigs as influenced through singular or combined consumption of Lactobacillus plantarum and inulin. J Anim Sci 90, 3848-3857.

23. Lee C, Kim J, Shin SG, et al. (2006) Absolute and relative qPCR quantification of plasmid copy number in Escherichia coli. J Biotechnol 123, 273-280.

24. Chomczynski P \& Sacchi N (2006) The single-step method of RNA isolation by acid guanidinium thiocyanate-phenolchloroform extraction: twenty-something years on. Nat Protoc 1, 581-585. 
25. Sweeney T, Collins B, Reilly P, et al. (2012) Effect of purified $\beta$-glucans derived from Laminaria digitata, Laminaria hyperborea and Saccharomyces cerevisiae on piglet performance, selected bacterial populations, volatile fatty acids and pro-inflammatory cytokines in the gastrointestinal tract of pigs. Br J Nutr 108, 1226-1234.

26. Leonard SG, Sweeney T, Bahar B, et al. (2012) Effect of maternal seaweed extract supplementation on suckling piglet growth, humoral immunity, selected microflora, and immune response after an ex vivo lipopolysaccharide challenge. J Anim Sci 90, 505-514.

27. Ryan MT, Collins CB, O'Doherty JV, et al. (2010) Selection of stable reference genes for quantitative real-time PCR in porcine gastrointestinal tissues. Livest Sci 133, 42-44.

28. Vandesompele J, De Preter K, Pattyn F, et al. (2002) Accurate normalization of real-time quantitative RT-PCR data by geometric averaging of multiple internal control genes. Genome Biol 3, research0034.

29. Hellemans J, Mortier G, De Paepe A, et al. (2007) qBase relative quantification framework and software for management and automated analysis of real-time quantitative PCR data. Genome Biol 8, R19.

30. Usov AI, Smirnova GP \& Klochkova NG (2001) Polysaccharides of algae: 55. Polysaccharide composition of several brown algae from Kamchatka. Russ J Bioorg Chem 27, 395-399.

31. Van Soest PJ, Robertson JB \& Lewis BA (1991) Methods for dietary fiber, neutral detergent fiber and nonstarch polysaccharides in relation to animal nutrition. J Dairy Sci $\mathbf{7 4}$, $3583-3597$.

32. SAS (2004) SAS Users Guide, 9.1.2 ed. Cary, NC: SAS Institue, Inc.

33. Pluske JR, Thompson MJ, Atwood CS, et al. (1996) Maintenance of villus height and crypt depth, and enhancement of disaccharide digestion and monosaccharide absorption, in piglets fed on cows' whole milk after weaning. Br J Nutr 76, 409-422.

34. Montagne L, Pluske JR \& Hampson DJ (2003) A review of interactions between dietary fibre and the intestinal mucosa, and their consequences on digestive health in young non-ruminant animals. Anim Feed Sci Technol 108, 95-117.

35. Melin L, Mattsson S, Katouli M, et al. (2004) Development of post-weaning diarrhoea in piglets. Relation to presence of Escherichia coli strains and rotavirus. J Vet Med B 51, 12-22.

36. Hogaboam CM, Steinhauser ML, Schock H, et al. (1998) Therapeutic effects of nitric oxide inhibition during experimental fecal peritonitis: role of interleukin-10 and monocyte chemoattractant protein 1. Infect Immun 66, 650-655.

37. Mckay DM \& Baird AW (1999) Cytokine regulation of epithelial permeability and ion transport. Gut 44, 283-289.

38. Li J, Li DF, Xing JJ, et al. (2006) Effects of $\beta$-glucans extracted from Saccharomyces cerevisiae on growth performance, and immunological and somatotropic responses of pigs challenged with Escherichia coli lipopolysaccharide. J Anim Sci 84, 2374-2381.

39. Nataro JP \& Kaper JB (1998) Diarrheagenic Escherichia coli. Clin Microbiol Rev 11, 142-201.

40. Janke BH, Francis DH, Collins JE, et al. (1989) Attaching and effacing Escherichia coli infections in calves, pigs, lambs, and dogs. $J$ Vet Diagn Invest 1, 6-11.

41. An H, Fairbrother JM, Désautels C, et al. (2000) Presence of the LEE (locus of enterocyte effacement) in pig attaching and effacing Escherichia coli and characterization of eae, espA, $e s p B$ and espD genes of PEPEC (pig EPEC) strain 1390. Microb Pathog 28, 291-300.

42. Fairbrother JM, Nadeau É \& Gyles CL (2005) Escherichia coli in postweaning diarrhea in pigs: an update on bacterial types, pathogenesis, and prevention strategies. Anim Health Res Rev 6, 17-39.

43. Kogan G \& Kocher A (2007) Role of yeast cell wall polysaccharides in pig nutrition and health protection. Livest Sci 109, 161-165.

44. Wen L, Ley RE, Volchkov PY, et al. (2008) Innate immunity and intestinal microbiota in the development of type 1 diabetes. Nature 455, 1109-1113.

45. Kinnebrew MA \& Pamer EG (2012) Innate immune signaling in defense against intestinal microbes. Immunol Rev $\mathbf{2 4 5}$, 113-131.

46. Stecher B, Robbiani R, Walker AW, et al. (2007) Salmonella enterica serovar Typhimurium exploits inflammation to compete with the intestinal microbiota. PLoS Biol 5, 2177-2189.

47. O'Shea CJ, Sweeney T, Lynch MB, et al. (2011) Modification of selected bacteria and markers of protein fermentation in the distal gastrointestinal tract of pigs upon consumption of chitosan is accompanied by heightened manure odor emissions. J Anim Sci 89, 1366-1375.

48. Mortensen PB \& Clausen MR (1996) Short-chain fatty acids in the human colon: relation to gastrointestinal health and disease. Scand J Gastroenterol 31, 132-148.

49. Macfarlane S \& Macfarlane GT (2003) Regulation of shortchain fatty acid production. Proc Nutr Soc 62, 67-72.

50. Macfarlane GT, Gibson GR, Beatty E, et al. (1992) Estimation of short-chain fatty acid production from protein by human intestinal bacteria based on branched-chain fatty acid measurements. FEMS Microbiol Lett 101, 81-88.

51. Sauvant D, Perez JM \& Tran G (2004) Table of Composition and Nutritional Value of Feed Materials. Pigs, Poultry, Cattle, Sheep, Goats, Rabbits, Horses, Fish. Wageningen: Wageningen Academic Publishers.

52. Metzler-Zebeli BU, Hooda S, Pieper R, et al. (2010) Nonstarch polysaccharides modulate bacterial microbiota, pathways for butyrate production, and abundance of pathogenic Escherichia coli in the pig gastrointestinal tract. Appl Environ Microbiol 76, 3692-3701.

53. Leverton LQ \& Kaper JB (2005) Temporal expression of enteropathogenic Escherichia coli virulence genes in an in vitro model of infection. Infect Immun 73, 1034-1043. 